\title{
An atmosphere-wave regional coupled model: improving predictions of wave heights and surface winds in the southern North Sea
}

\author{
Kathrin Wahle $^{1}$, Joanna Staneva ${ }^{1}$, Wolfgang Koch ${ }^{1}$, Luciana Fenoglio-Marc ${ }^{2}$, Ha T. M. Ho-Hagemann ${ }^{1}$, and \\ Emil V. Stanev ${ }^{1}$ \\ ${ }^{1}$ Institute of Coastal Research, Helmholtz-Zentrum Geesthacht, Geesthacht, Germany \\ ${ }^{2}$ Institute of Geodesy and Geoinformation, University of Bonn, Bonn, Germany \\ Correspondence to: Kathrin Wahle (kathrin.wahle@hzg.de) and Joanna Staneva (joanna.staneva@hzg.de)
}

Received: 22 June 2016 - Discussion started: 28 June 2016

Revised: 14 February 2017 - Accepted: 14 March 2017 - Published: 13 April 2017

\begin{abstract}
The coupling of models is a commonly used approach when addressing the complex interactions between different components of earth systems. We demonstrate that this approach can result in a reduction of errors in wave forecasting, especially in dynamically complicated coastal ocean areas, such as the southern part of the North Sea - the German Bight. Here, we study the effects of coupling of an atmospheric model (COSMO) and a wind wave model (WAM), which is enabled by implementing wave-induced drag in the atmospheric model. The numerical simulations use a regional North Sea coupled wave-atmosphere model as well as a nested-grid high-resolution German Bight wave model. Using one atmospheric and two wind wave models simultaneously allows for study of the individual and combined effects of two-way coupling and grid resolution. This approach proved to be particularly important under severe storm conditions as the German Bight is a very shallow and dynamically complex coastal area exposed to storm floods. The two-way coupling leads to a reduction of both surface wind speeds and simulated wave heights. In this study, the sensitivity of atmospheric parameters, such as wind speed and atmospheric pressure, to the wave-induced drag, in particular under storm conditions, and the impact of two-way coupling on the wave model performance, is quantified. Comparisons between data from in situ and satellite altimeter observations indicate that two-way coupling improves the simulation of wind and wave parameters of the model and justify its implementation for both operational and climate simulations.
\end{abstract}

\section{Introduction}

Wind forcing is considered one of the largest error sources in wave modelling. In numerical atmospheric models, wind stress is parameterised by the drag coefficient usually considered spatially uniform over water. In reality however the wind waves extract energy and momentum from the atmosphere as they grow under the influence of wind. This effect is greater for young sea states and high wind speed in comparison to decaying sea and calm atmospheric conditions. Under such conditions, the drag coefficient cannot be considered independent of the sea state and uniform in time and space. This dependence needs to be accounted for in coupled atmosphere-wave models. Jenkins et al. (2012) demonstrated that the wave field alters the ocean's aerodynamic roughness and the air-sea momentum flux depending on the relationship between the surface wind speed and the propagation speed of wave crests (the wave age). Based on high-resolution coupled simulations, Doyle (1995) demonstrated that young ocean waves increase the effective surface roughness, decrease the $10 \mathrm{~m}$ wind speed, and modulate heat and moisture transports between the atmosphere and ocean. As a result of this boundary layer modification Doyle (1995) concluded that the mesoscale structures associated with cyclones are perturbed. The impact of sea surface roughness was investigated in studies by Bao et al. (2002) and Desjardins et al. (2000). As shown by Lionello et al. (1998), the two-way wave-atmosphere coupling attenuates the depth of the pressure minimum. In particular, non-linearities increase under extreme conditions, which can modify the intensity of 
storms due to feedbacks between waves and the atmosphere. This feedback needs to be accounted for in coupled models as strong winds cause the drag coefficient of the sea surface to increase, leading to a reduction of wind speeds and modification of wind directions (Warner et al., 2010). These effects feed back into the airflow, wind speed, and turbulence profile in the boundary layer. Zweers et al. (2010) showed that the used atmospheric model overestimates the surface drag for high wind speeds and underestimates the intensity of hurricane winds. Zweers et al. (2010) proposed an approach of calibrating the boundary layer parameterisation using a one-way coupled model. They tested a new parameterisation that decreased the surface drag for two hurricanes in the Caribbean. This new drag parameterisation leads to much stronger forecasted hurricanes, which were in good agreement with observations.

The coupling between atmospheric and wind wave models was first introduced operationally in 1998 by the European Centre for Medium-Range Weather Forecasts (ECMWF). The method based on the theoretical work of Janssen (1991) contributed to an improvement of both atmospheric and surface wave forecasts on the global scale. Waves were recently considered in operational coupled model systems, such as that of Meteo-France (Voldoire et al., 2013). Breivik et al. (2015) incorporated the effects of surface waves into ocean dynamics via ocean side stress, turbulent kinetic energy due to wave breaking, and the Stokes-Coriolis force in the ECMWF system.

The effect of coupling on model predictions becomes more important (Janssen et al., 2004) with increasing grid resolution, which therefore emphasises the need for coupling on the regional scales. Spatial and temporal changes in the wave and wave energy propagation are not yet sufficiently addressed in high-resolution regional atmospheric models. The shallow water terms in the wave equations (depth and current refraction, bottom friction and wave breaking) play a dominant role near coastal areas, especially during storm events, where the wave breaking term prevents unrealistically high waves near the coast. The spray caused by breaking waves modulates the atmosphere boundary layer. Air-sea interaction is also of great importance in regional climate modelling. Rutgersson et al. $(2010,2012)$ introduced two different parameterisations in a European climate model. One parameterisation uses roughness length and includes only the effect of a growing sea, as proposed by Janssen (1991). The other uses wave age and introduced the reduction of roughness due to swell. In both cases, these parametrisations affected the long-term averages of atmospheric parameters notably and demonstrated that the swell has an important impact on mixing in the boundary layer. Järvenoja and Tuomi (2002) emphasised the necessity to use wind data with fine temporal discretisation in the wave model in the Baltic Sea and found that the impact of the coupled model on the meteorological part of the model can mainly be seen in predicted surface winds. For the Mediterranean
Sea, Cavaleri et al. (2012) found that reduced wind speeds were compensated by a limited deepening of the pressure fields of atmospheric cyclones. Lionello et al. (2003) demonstrated the importance of the atmosphere-wave interaction by studying the sea surface roughness feedback on momentum flux. A coupled ocean-atmosphere-wave-sediment transport (COAWST) modelling system has been developed for the coastal ocean (Warner et al., 2010; Kumar et al., 2012). For the Balearic Sea, Renault et al. (2012) compared atmospheric and oceanic observations and showed that the use of COAWST improved their simulations, especially for storm events. Recently, high-resolution, regional, and fully coupled models have been further developed, as shown by Katsafados et al. (2016), who used the Mediterranean Sea as an example. They focused on air-sea momentum fluxes under conditions of extremely strong and time-variable winds and demonstrated that by including the sea state dependent drag coefficient, effects on a wave spectrum and their feedback on momentum flux lead to improved model predictions. For the southern North Sea (the German Bight area), Staneva et al. (2016) showed the effect of wave-induced forcing on sea level variability and hydrodynamics, although wave-atmosphere interaction processes were not considered.

Model outputs can be validated against in situ and spacebased observational data from satellite altimetry. Particularly challenging for the significant wave height estimations are coastal data, due to land and calm water interference in the altimeter footprint and in low sea states (Fenoglio-Marc et al., 2015). Analyses of the differences between altimeter and in situ measurements over time intervals of several months provide an estimate of the accuracy of altimeter data relative to in situ data assumed as ground truth. Significant wave heights derived from satellite altimetry over an interval of 10 years (2002-2012) have been compared to wave height measurements from several waveriders in Passaro et al. (2015). Fenoglio-Marc et al. (2015) considered 2 years (2012-2013) of the CryoSat-2 satellite mission to estimate the accuracy of both significant wave height and wind speed.

In this study, we aim at a quantification of the effects of coupling of wave and atmospheric models, also during extreme storm events. We compare simulations between coupled and stand-alone models that we validate with newly available space-based observational data. In the one-way coupled set-up, the wind wave model only receives wind data from the atmospheric model. In the two-way coupled set-up, the wind wave model sends the computed sea surface roughness back to the atmospheric model. Then, we statistically assess the impact of the two-way coupling and validate the two set-ups against available in situ and remote sensing data. Our novel contribution here is that we simultaneously run (via a coupler) a regional North Sea coupled wave-atmosphere model together with a nested-grid high resolution in the German Bight wave model (one atmospheric model and two wind wave models). Using this configuration allows us to study the individual and combined effects of (1) model cou- 
pling and (2) grid resolution, especially under severe storm conditions, which is a challenging aspect for wave modelling at the German Bight because it is a very shallow and dynamically complex coastal area.

The paper is structured as follows. In Sect. 2 we describe the models used, the coupling and specification of different model set-ups, the period of model integration, and available data for validation. Afterwards, we validate the models against satellite and in situ measurements in Sect. 3. Section 4 discusses the impact of two-way coupling. The final section summarises our findings and also provides an outlook for future research.

\section{Model description and set-up}

\subsection{The COSMO atmospheric model}

The atmospheric model used in this study is the COSMOCLM (CCLM) version 4.8 non-hydrostatic regional climate model (Rockel et al., 2008; Baldauf et al., 2011). The model is developed and applied by a number of national weather services affiliated with the Consortium for Small-Scale Modeling (COSMO; see also http://www2.cosmo-model.org/). Its climate model, COSMO-CLM (CCLM), is used by the Climate Limited-area Modelling Community (http:// www.clm-community.eu/). CCLM is based on the primitive thermo-hydrodynamical equations that describe compressible flow in a moist atmosphere. The model equations are formulated in rotated geographical coordinates with generalised terrain following vertical coordinates. The model uses the primitive momentum equations. The continuity equation is replaced by a prognostic equation for perturbation pressure (i.e. pressure deviation from a reference state representing a time-independent dry atmosphere at rest, which is prescribed as horizontally homogeneous, vertically stratified and in hydrostatic balance).

In our set-up, we use a spatial resolution of $\sim 10 \mathrm{~km}$ and 40 vertical levels to discretise the area around the North Sea and Baltic Sea (Fig. 1a). Forcing and boundary condition data are taken from the coastDat-2 hindcast database for the North Sea (Geyer, 2014) covering the period 1948-2013 with a spatial resolution of $\sim 24 \mathrm{~km}\left(0.22^{\circ}\right)$ and a temporal resolution of $6 \mathrm{~h}$.

\subsection{The WAM wave model}

WAM Cycle 4.5.4 is an update of the third-generation WAM Cycle4 wave model (Komen et al., 1994). The basic physics and numerics are maintained in the new release. The source function integration scheme of Hersbach and Janssen (1999) and the reformulated wave model dissipation source function of Bidlot et al. (2007) and Janssen (2008) are incorporated. Depth-induced wave breaking (Battjes and Janssen, 1978) has been included as an additional source function. Depth and/or current fields can be non-stationary.

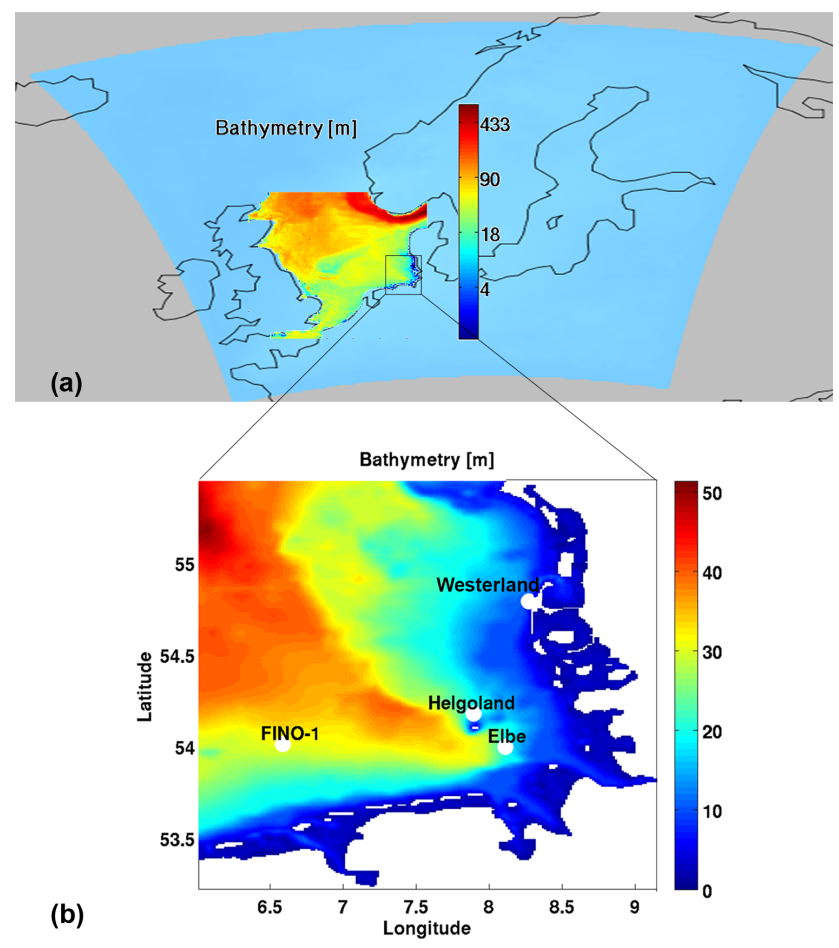

Figure 1. (a) Bathymetry (m) of the North Sea embedded in the COSMO model area (using a logarithmic scale) and (b) bathymetry (m) of the German Bight as used in the WAM model. The positions of four waverider buoys used for the validation are indicated, too.

The nested-grid set-up includes a regional wave model for the North Sea with a spatial resolution of $\sim 5 \mathrm{~km}$ (Fig. 1a) and a finer wave model for the German Bight with a resolution of $\sim 900 \mathrm{~m}$ (Fig. 1b). These models (described in Staneva et al., 2015) use a directional resolution of $15^{\circ}$ and 30 frequencies with an equidistant relative resolution ranging from 0.04 to 0.66 . The boundary values for the North Sea model are taken from the EWAM (European WAM) regional model of the German Weather Service (DWD). The forcing wind data are provided by CCLM (see Sect. 2.1). The German Bight wave model uses boundary values of the outer North Sea model and accounts additionally for depthinduced wave breaking and depth refraction. The sea state dependent roughness length, according to Janssen (1991), has already been implemented in WAM-4.5.4. Thus for the present study, the model only needed to be adapted for usage with the OASIS3-MCT coupler (see Sect. 2.3).

\subsection{Coupling of models}

WAM and CCLM are coupled via the OASIS3-MCT version 2.0 coupler (Valcke et al., 2013). The name OASIS3MCT is a combination of OASIS3 (the Ocean, Atmosphere, Sea, Ice, and Soil model coupler version 3) from the European Centre for Research and Advanced Training in Scien- 
tific Computation (CERFACS) and MCT (the Model Coupling Toolkit) that were developed by Argonne National Laboratory in the USA. Details of properties and usage of the OASIS3 coupler can be found in Valcke (2013). Exchanged fields between the atmospheric and wave models in this study are wind and sea surface roughness length. For the coupling with OASIS3 the modifications in the atmospheric model are as in Ho-Hagemann et al. (2013), and in the WAM wave model as in Staneva et al. (2016).

We perform one-way and two-way coupled simulations. In the one-way coupled model, the atmospheric model provides wind data for the North Sea wave model via OASIS. This is equivalent to the familiar forcing of a wave model by $10 \mathrm{~m}$ wind fields. We will refer to the results of these simulations as COSMO-1wc and WAM-NS-1wc, where "1wc" and 'NS' stand for "one-way coupled" and "North Sea", respectively. In the two-way coupled model, the North Sea wave model is forced with winds provided by the atmospheric model and the sea surface roughness lengths are sent back to the atmospheric model, which in return might change the wind speeds. We will refer to the results of these simulations as COSMO-2wc and WAM-NS-2wc, respectively. The coupling time step is $3 \mathrm{~min}$ for all the simulations. This short time step is a great advantage when modelling fast moving storms in comparison to using stand-alone wave models forced by winds, which are usually available in hourly time steps.

The high-resolution German Bight wave model, which also runs simultaneously with CCLM and the North Sea WAM, is forced in the two simulations by the CCLM wind and the boundary data provided by the North Sea WAM set-up. We will refer to the two differently forced set-ups as WAM-GB-1wc and WAM-GB-2wc. In the second experiment roughness information is sent to the atmospheric model by WAM-NS-2wc, while it is not in the first experiment. Compared to previous atmosphere-wave coupling research, our study is novel as we are able to simultaneously run a high-resolution coastal model (the German Bight one) that uses winds and lateral forcing provided by the coupled regional atmosphere (COSMO-2wc) and wave (WAM-NS$2 \mathrm{wc})$ models.

\subsection{Study period and data availability}

The coupled wave-atmosphere model system described in the previous section was used to simulate a 3-month period from October to December 2013. This period was chosen because it includes the time when storm Xaver passed over the study area on 6 December 2013. This was one of the most severe storms of the last decade, which originated south of Greenland and rapidly deepened as it moved eastwards from Iceland over the Norwegian Sea to southern Sweden and further to the Baltic Sea and Russia. At the German Bight, the arrival of Xaver coincided in time with a high tide. Because of the high tide and wind gusts of greater than $130 \mathrm{~km} \mathrm{~h}^{-1}$,

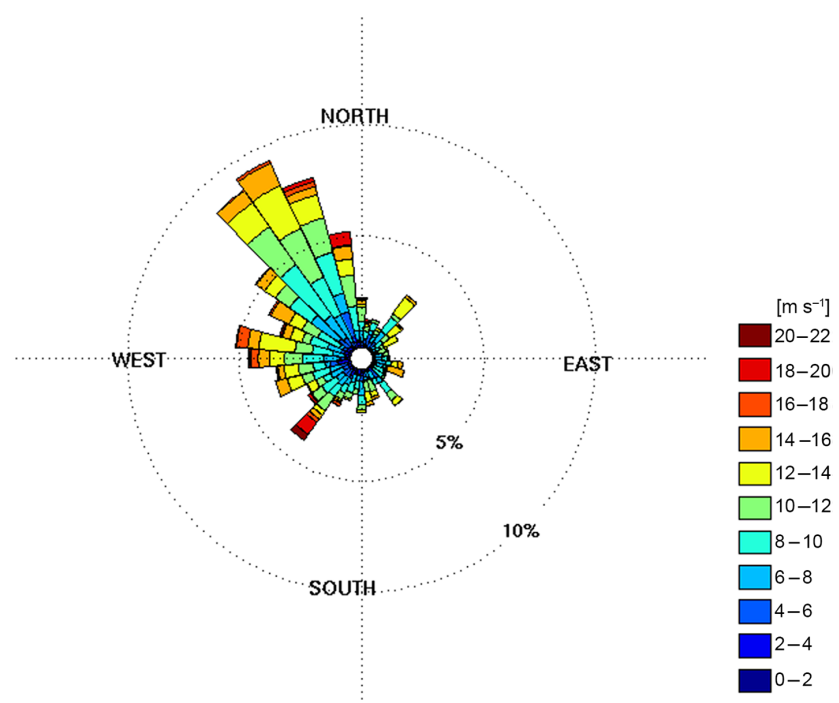

Figure 2. Distribution of frequency and wind speeds in $\mathrm{ms}^{-1}$ (see colour bar) and wind direction at the FINO-1 waverider buoy for the period of 1 October until 31 December 2013.

an extreme weather warning was given to the coastal areas of north-western Germany (Deutschländer et al., 2013). This storm event was also exceptional because of its long duration of nearly 2 days. The surge height reached $\sim 2.5 \mathrm{~m}$, with its maximum at low tide. During Xaver, two surge maxima were observed (Staneva et al., 2016). Fenoglio-Marc et al. (2015) described the first surge maximum as a locally generated surge. They found that the surge derived from the tide gauge records at Aberdeen and Lowestoft stations had only one maximum, reaching the eastern North Sea coastal areas (anticlockwise propagation) approximately $10 \mathrm{~h}$ later than at Lowestoft (easternmost UK coast). This caused the second storm surge maximum, which was detected by the measurements in the German Bight (surge generated further away and propagated to the study area). As demonstrated by Staneva et al. (2016), the wave-induced mechanisms contributed to a persistent increase in the surge after the first maximum (with a slight overestimation after the second peak).

In the present study, we perform statistical analyses for the whole integration period and investigate the period of the Xaver extreme storm event in more detail. The distribution of wind speeds and directions over the selected period as seen in the waverider data from the FINO-1 in situ platform (see Fig. 1b for its location) is shown in Fig. 2. North-westerly winds are generally dominant, but strong winds (higher than $20 \mathrm{~m} \mathrm{~s}^{-1}$ ) came from the west and southwest as the Xaver storm moved eastwards. South-easterly and north-easterly winds are rarely observed at the FINO-1 station.

To validate our experiments, we use wind speed and significant wave height data measured by satellite altimeters SARAL/AltiKa, Jason-2 and CryoSat-2 over the North Sea (see Fig. 3 with the tracks of the different satellites 


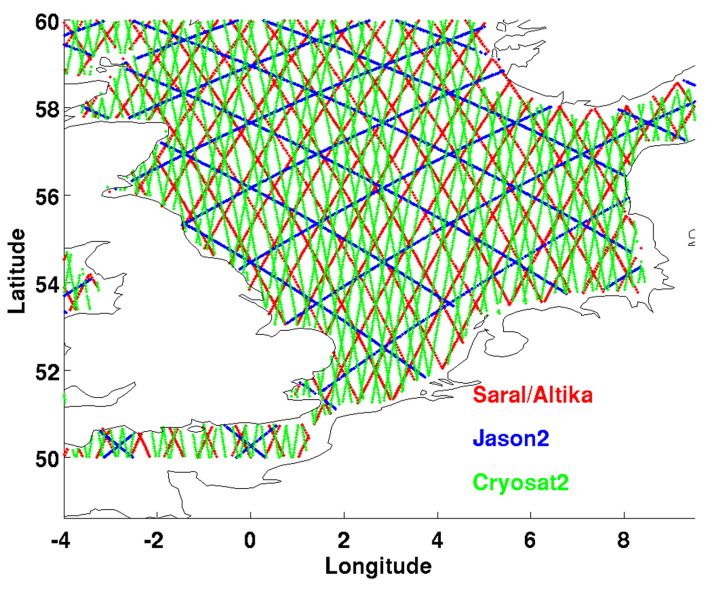

Figure 3. Tracks of all satellites during the study period (1 October until 31 December 2013).

over the 3-month study period). The first two carry classical pulse-limited altimeters that operate in low-resolution mode (LRM), while the CryoSat-2 altimeter operates either in LRM or in synthetic aperture radar (SAR) mode, also called delay Doppler altimetry (DDA), depending on the operational mask. In our region of analysis the mask was always in SAR mode and the CryoSat-2 data used are the pseudo-LRM (PLRM) data extracted from the RADS database (Scharroo et al., 2013). The accuracy and precision of PLRM data are slightly lower than LRM and SAR data (Smith and Scharroo, 2015). The altimeter satellites observe along their ground-track offshore up to a few kilometres from the coast (Fig. 3). Their ground track pattern and repeat period are different for each of the three missions, as the same location is revisited by each mission every 27 , 10, and 350 days (Chelton et al., 2001). The SARAL/AltiKa data are of special interest in our study because this satellite passed over the German Bight during storm Xaver when the surge was at its maximum (Fenoglio-Marc et al., 2015). The in situ wave data of four directional waveriders in the German Bight are provided by the Federal Maritime and Hydrographic Agency (BSH) (see Fig. 1b for the buoy locations). The wind speed measurements close to the shore of the island of Sylt, near the Westerland buoy location, and on the island of Helgoland, are provided by the DWD. At station FINO-1 (see Fig. 1b for its location), there were also wind speed measurements available at 50 and $100 \mathrm{~m}$ a.s.l. (above sea level) for the selected period.

\section{Validation of the results}

\subsection{Altimeter data}

The long revisiting time of the same location and the global coverage could be considered intrinsic characteristics of the satellite altimetry. Therefore, a longer interval of analysis
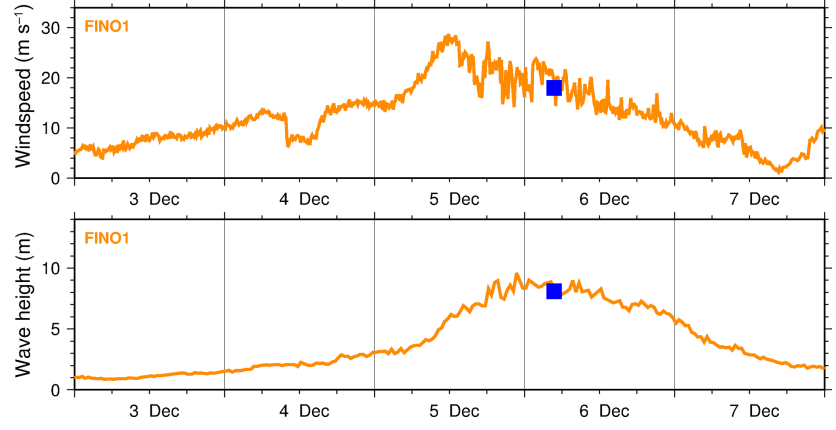

Figure 4. Time series during 5 days, which include storm Xaver of the observations in station FINO-1 (orange line) together with the Saral/Altika observation (blue full square). Top panel: wind speed $\left(\mathrm{m} \mathrm{s}^{-1}\right)$; and bottom panel: significant wave height $(\mathrm{m})$. SARAL/AltiKa passed over the German Bight during storm Xaver when the surge was at its maximum (the data during the overflight are plotted with a full blue mark).

is needed when analysing the agreement between altimeter and in situ measurements, collected from waveriders and anemometers. The tracks during the study period for the three different satellites are illustrated in Fig. 3. Wind speed and significant wave height data measured at the FINO-1 station during the 5-day period (2-7 December 2013). The nearest point observations of the SARAL/Altika satellite altimeter as it passed over the region at 05:45 UTC on 6 December (see also Fenoglio-Marc et al., 2015) are specified with the blue mark also in Fig. 4. The wave height and wind speed measured by the SARAL/Altika altimeter (blue symbol) during the Xaver storm are in good agreement with in situ observations.

The differences between the altimeter and in situ measurements over longer time intervals provide an estimate of the accuracy of the altimeter data relative to the in situ data assumed as ground truth. Fenoglio-Marc et al. (2015) considered wave height and wind speed derived from CryoSat-2 SAR altimetry data located in the open sea at a distances between 10 and $20 \mathrm{~km}$ from in situ stations of the network in the German Bight and found accuracies of about $15 \mathrm{~cm}$ for the wave height and $1.8 \mathrm{~m} \mathrm{~s}^{-1}$ for the wind speed. They also found a good consistency between pseudo-conventional (PLRM) and SAR data in the open ocean, with standard deviations (SDs) between PLRM and SAR of $21 \mathrm{~cm}$ and $0.26 \mathrm{~m} \mathrm{~s}^{-1}$ for wave height and wind speed, respectively. In situ analysis showed a higher accuracy in significant wave height for SAR compared to PLRM. As a demonstration, Fig. 5 shows the scatterplots for FINO-1 and CryoSat-2 SAR and PLRM measurements. For the significant wave height, SAR has higher accuracy than the standard PLRM (SDs with in situ data are 18 and $30 \mathrm{~cm}$, respectively). For the wind speed the accuracies of SAR and PLRM are similar and equal to $1.9 \mathrm{~m} \mathrm{~s}^{-1}$. The accuracy in the significant wave height from PLRM increases (SD is $19 \mathrm{~cm}$ ) when a dedicated re- 

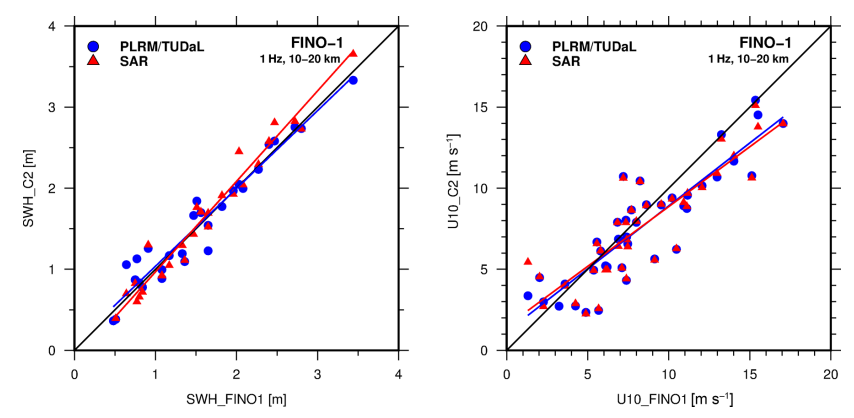

Figure 5. Comparison at station FINO-1 of in situ and altimeterderived (a) significant wave height and (b) wind speed of in situ and co-located altimeter measurements at the FINO-1 station. Altimeter data are SAR (triangle) and PLRM (circle).

tracking procedure is applied (Fenoglio-Marc et al., 2015). Figure $5 \mathrm{~b}$ shows an underestimation of wind speed of altimetry relative to the in situ data (the slope is below 0.8 in all cases).

\subsection{Altimeter-model comparisons}

In this section, we quantify the performance of one-way vs. two-way coupling by comparing the output of the atmospheric and wave models against remotely sensed data. Table 1 gives the statistics of the differences (bias and standard deviations) between the model and altimeter-derived values of wave height and wind speed over the selected 3-month period. The numbers of matched pairs (approximately 7000) of observations and simulations are also given in Table 1 for the different satellites.

For all three satellites, the standard deviation in the twoway coupled model is smaller than in the one-way coupled model. For Jason-2 and SARAL/Altika, the bias in the twoway coupled model is nearly halved compared to the bias in the one-way model. Measured values are lower than the modelled values in the one-way and two-way experiments.

For Cryosat-2, by contrast, the measured values are higher than the modelled values on average for both the wave height and wind speed. The biases between the CryoSat- 2 data and the two-way model simulations (see the red shaded values in Table 1) are larger than the biases between the CryoSat-2 data and the one-way model runs. Fenoglio-Marc et al. (2015) also found that the CryoSat-2-derived wave height data overestimate the wave model data from the DWD. However, they found the opposite for the wind speed, i.e. the CryoSat2-derived wind speed underestimates the COSMO winds from the DWD data. The difference between our results and Fenoglio-Marc et al. (2015) is due to the different data that have been used to force the atmospheric models by the DWD and this study.

To perform a spatial comparison between model simulations and the satellite data, we analysed individual tracks over the North Sea, and two of these are shown in Figs. 6
Table 1. Bias and standard deviation of validation of wind speed $\left(\mathrm{m} \mathrm{s}^{-1}\right)$ and significant wave height $(\mathrm{m})$ of the one- and twoway coupled models against the available satellite data over the whole period (measured minus modelled). Bold means an improvement of the two-way coupled model skills; italic means that the one-way coupled model skill is better than the ones of the two-way coupled model.

\begin{tabular}{|c|c|c|c|c|}
\hline & \multicolumn{2}{|c|}{ Significant wave height $(\mathrm{m})$} & \multicolumn{2}{|c|}{ Wind speed $\left(\mathrm{m} \mathrm{s}^{-1}\right)$} \\
\hline & One-way & Two-way & One-way & Two-way \\
\hline \multicolumn{5}{|c|}{ Saral/AltiKa no. 6886} \\
\hline Mean meas. & \multicolumn{2}{|c|}{2.35} & \multicolumn{2}{|c|}{9.76} \\
\hline Bias & -0.27 & -0.12 & -0.64 & -0.33 \\
\hline SD & 0.93 & 0.86 & 3.33 & 3.16 \\
\hline \multicolumn{5}{|c|}{ Jason-2 no. 6710} \\
\hline Mean meas. & \multicolumn{2}{|c|}{2.38} & \multicolumn{2}{|c|}{9.62} \\
\hline Bias & -0.29 & -0.15 & -0.73 & -0.40 \\
\hline SD & 1.07 & 1.01 & 3.85 & 3.75 \\
\hline \multicolumn{5}{|c|}{ Cryosat-2 no. 7477} \\
\hline Mean meas. & \multicolumn{2}{|c|}{2.71} & \multicolumn{2}{|c|}{10.62} \\
\hline Bias & 0.18 & 0.31 & 0.39 & 0.65 \\
\hline SD & 0.90 & 0.87 & 3.33 & 3.18 \\
\hline
\end{tabular}

and 7. The satellite altimetry observations along the ground track at the time of the overflight at the German Bight last $\sim 38 \mathrm{~s}$. The selected SARAL/AltiKa passes are very diverse, as one was taken under calm conditions (Fig. 6) and the other during storm Xaver (Fig. 7), which therefore provided an opportunity to compare measured and modelled wave heights and wind speeds along the satellite tracks under different atmospheric and wave conditions illustrated in Figs. 6 and 7. Under calm conditions, differences between the results of the one- and two-way coupling are very small (Fig. 6a). Both models (WAM-NS-1wc and WAM-NS-2wc) overestimate the measured wave height (red line) over a large part of the track. However, the increase in modelled wave height with increasing latitude appears to be consistent with the northward wind speed increase observed by the satellite data and simulated in the two simulations (Fig. 6b). During storm Xaver, the difference between the wave height in the WAMNS-1wc and WAM-NS-2wc simulations (Fig. 7a) increases up to $1 \mathrm{~m}$ in the southern North Sea. The altimeter-derived quantities fluctuate greatly. However, the two-way coupledmodel results are closer to the satellite data, in comparison to the ones in WAM-NS-1 $\mathrm{wc}$, except for the latitude of $\sim 56^{\circ} \mathrm{N}$, where the significant wave height from the satellite measurements has a local peak. The modelled significant wave height (black lines) is much smoother than the satellite observations (red line), which can be explained by the fact that the model is not capable of resolving the small scales seen in the satellite observations. The corresponding wind speed does not grow at this latitude, neither for the measured nor for the modelled wind speeds. It is noteworthy that both model 


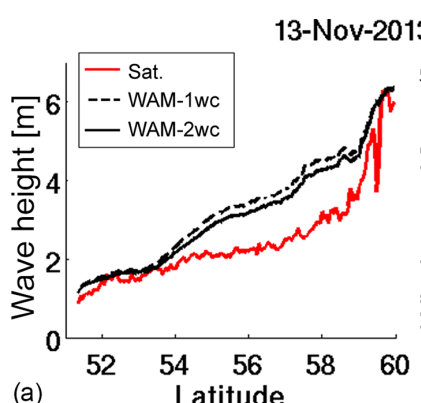

(a)

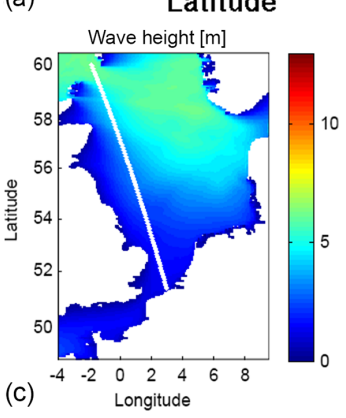

Figure 6. Time series of wave height $(\mathrm{m})$ and wind speed $\left(\mathrm{m} \mathrm{s}^{-1}\right)$ from the Saral/AltiKa data and as modelled by WAM-NS under calm weather conditions on 13 November 2013. The track of the satellite (the white line) is shown together with the model significant wave height at the time of the passage (bottom panel).

experiments missed the peak in measured significant wave height above $58^{\circ} \mathrm{N}$ (Fig. 7a).

The modelled wind speed fits well the altimeter-derived data during calm conditions in both experiments (COSMO$1 \mathrm{wc} / 2 \mathrm{wc}$, Fig. $6 \mathrm{~b}$ ). Northwards of $55^{\circ} \mathrm{N}$, the wind speed is higher than $10 \mathrm{~m} \mathrm{~s}^{-1}$, while the wind speed in the twoway coupled experiment (COSMO-2wc, full line) is slightly lower than in COSMO-1wc. During storm Xaver, the measured wind data fluctuate $\sim 18 \mathrm{~m} \mathrm{~s}^{-1}$, whereas the modelled data show much higher values of $\sim 20 \mathrm{~m} \mathrm{~s}^{-1}$, reaching $\sim 22 \mathrm{~m} \mathrm{~s}^{-1}$ at $\sim 57$ and $59^{\circ} \mathrm{N}$ (Fig. 7b). This confirms the findings of Fenoglio-Marc et al. (2015), who had compared the same altimeter data with ERA-Interim, NOAA/GFC and COSMO/EU winds. They suggested that the low wind speeds derived from the altimeter are caused by an overestimation of the atmospheric attenuation of the radar power in the Ka-band. In fact a larger attenuation correction would result in too large a backscatter coefficient and hence reduced wind speed (Fenoglio-Marc et al., 2015). The correction in the SARAL/AltiKa products is larger than the correction based on surface pressure, near-surface temperature, and water vapour content (Lillibridge et al., 2014). Similar analyses along all tracks over the study period agree with the two examples demonstrated in Figs. 6 and 7. In general, the measured wind speeds were in slightly better agreement with the two-way coupled model results, which was also demonstrated by statistics presented in Table 1 . The track during
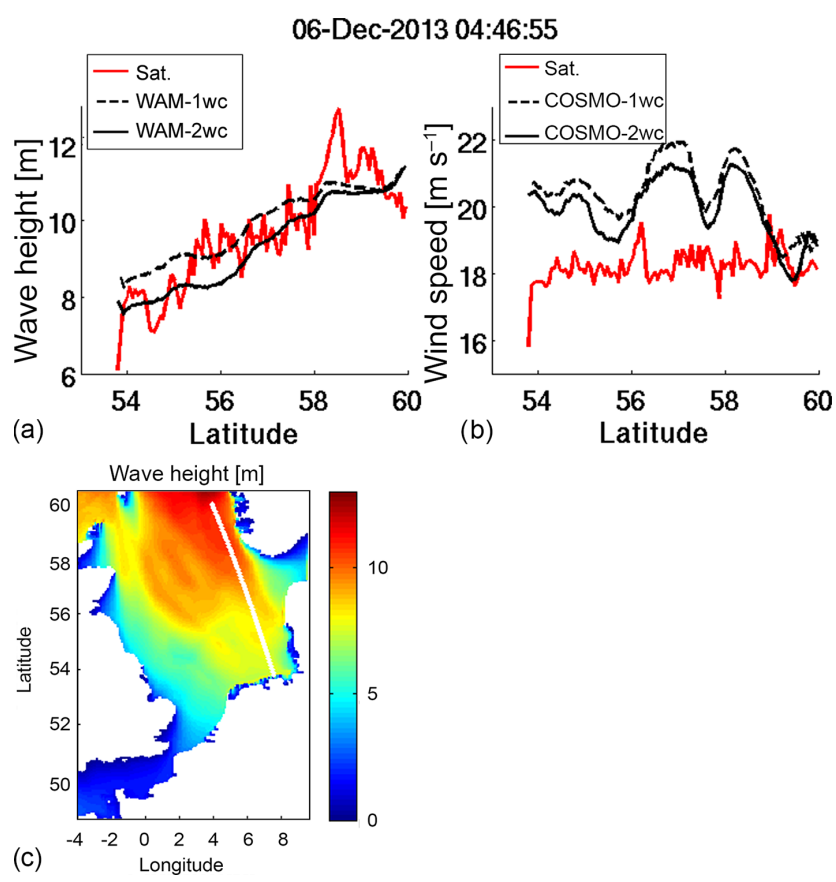

Figure 7. As Fig. 6 but for storm Xaver on 6 December 2013.

the time of storm Xaver was the only track taken under such extreme conditions.

\subsection{Validation against in situ measurements}

Analyses of the temporal variability of the significant wave heights in the German Bight under stormy conditions allow us to investigate not only the impact of two-way coupling, but also the role of the horizontal resolution. Figure 8 illustrates the time variability of the significant wave height (top panels) and the wind speed (bottom panels) at the Helgoland and Westerland stations (see Fig. 1b for locations) from observations (black line) and the different model runs during storm Xaver.

The wind fields in both locations are very similar in the COSMO- $1 \mathrm{wc} / 2 \mathrm{wc}$ model runs; the peak of the storm is reduced from 26 to $22 \mathrm{~m} \mathrm{~s}^{-1}$. By comparing the modelled and measured wind speeds, it is noticeable that the modelled wind speeds grow too early and too high at all locations at the beginning of the storm (see the bottom patterns in Fig. 8a and $\mathrm{b}$ for the Helgoland and Westerland examples). The storm characteristics are matched well at Helgoland but are slightly underestimated at Westerland. Still, the overall model performance at Westerland is satisfactory, considering the strongly fluctuating wind measurements. Similar behaviour is observed for the Elbe and FINO-1 (not shown here) wave buoy stations.

Throughout this period, the highest values of significant wave heights are simulated by the WAM-NS-1wc experiment. The lowest values, and closest to the observations, are 

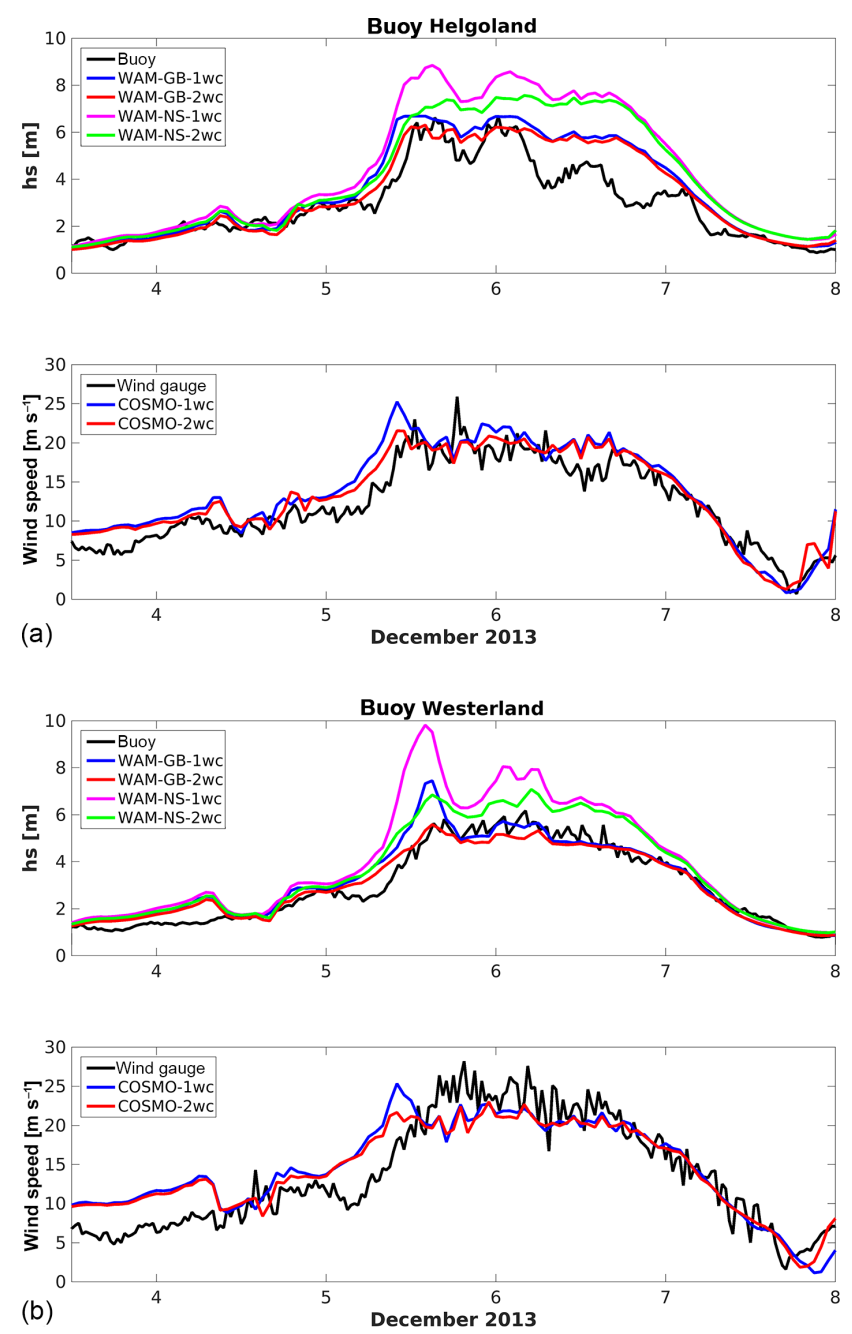

Figure 8. (a, b) Significant wave height (m, top panels) and wind speed $\left(\mathrm{m} \mathrm{s}^{-1}\right.$, bottom panels) during storm Xaver at the Helgoland (a) and Westerland/Sylt (b) buoys.

from the WAM-GB-2wc simulations (Fig. 8). At the beginning of December, during the calm atmospheric conditions, all model results are similar and fit relatively well with the in situ measurements. The differences in the wave growth between the different model simulations become notable after the storm onset. During the peak of the storm, the WAM-NS1wc simulation overestimates the measured wave heights by $\sim 3 \mathrm{~m}$ at the Helgoland station (water depth $30 \mathrm{~m}$, Fig. 8a) and by $\sim 4 \mathrm{~m}$ at the shallow water of the Westerland station (water depth 13 m, Fig. 8b). Compared to the in situ measurements, this peak occurs earlier in all simulations due to the time discrepancy between wind data and model time steps. The wave heights predicted by WAM-GB-2wc are in best agreement with the observations, especially for the Westerland station (Fig. 8b, the red line).

The influence of spatial resolution on the simulated characteristics can be clearly seen in the time series at the deep
Table 2. Wind speed $\left(\mathrm{m} \mathrm{s}^{-1}\right)$ bias and standard deviation of the oneand the two-way coupled COSMO model data against the FINO-1 data over the whole period (measured minus modelled). Bold means an improvement of the two-way coupled model skills.

\begin{tabular}{lccccc}
\hline & \multicolumn{2}{c}{$\begin{array}{c}\text { Wind speed }\left(\mathrm{m} \mathrm{s}^{-1}\right) \\
\text { at } 50 \mathrm{~m}\end{array}$} & & \multicolumn{2}{c}{$\begin{array}{c}\text { Wind speed }\left(\mathrm{m} \mathrm{s}^{-1}\right) \\
\text { at } 100 \mathrm{~m}\end{array}$} \\
\cline { 2 - 3 } \cline { 5 - 6 } & One-way & Two-way & & One-way & Two-way \\
\hline Mean meas. & \multicolumn{2}{c}{11.03} & & & \multicolumn{2}{c}{11.85} \\
Averaged difference & -0.67 & $\mathbf{- 0 . 4 1}$ & & -0.23 & $\mathbf{0 . 0 1}$ \\
rms difference & 3.26 & $\mathbf{3 . 1 7}$ & & 3.33 & $\mathbf{3 . 2 2}$ \\
\hline
\end{tabular}

water buoy at Helgoland, for which the differences between simulated wave heights during storm Xaver reach $\sim 1$ to $1.5 \mathrm{~m}$ in the corresponding North Sea and German Bight simulations (Fig. 8a). This buoy is located in an area of large gradients in water depth (Fig. 1b), where the high-resolution model uses a finer bathymetry at coastal areas with a rather complex shore (such as at Helgoland) leading to a better simulation of wave heights.

At the shallow Westerland buoy station (Fig. 8b) the differences are additionally enhanced by the depth-induced wave breaking in the German Bight model. This can also be seen in the snapshots of wave height in the North Sea and German Bight models at the peak of the storm (Fig. 9a and b). Shoreward of the $15 \mathrm{~m}$ isobaths, the wave heights drop from 6 to $4 \mathrm{~m}$ in the German Bight model. In contrast, for the North Sea model, the $6 \mathrm{~m}$ high waves reach the south-eastern coast. The WAM-NS-1wc model run underperforms in comparison to the WAM-NS-2wc simulation at Westerland. This underperformance further proves the importance of two-way coupling for the coastal German Bight areas, where the model wind speed is even higher (by $\sim 2 \mathrm{~m} \mathrm{~s}^{-1}$ ) than at Helgoland. We admit that it is difficult to differentiate between the effects due to wave breaking and two-way coupling because both contribute to reducing the wave height under extreme weather conditions. Wave breaking plays a dominant role in very shallow water, especially during storm events, by preventing unrealistically high waves near the coast. For deep waters, the sea surface roughness feedback due to the twoway coupling plays a very important role (Fig. 8a). The importance of the two-way coupling is clearly demonstrated by comparing WAM-GB-2wc (the blue line) and WAM-GB1wc (the red line) in Fig. 8. For all stations, the simulated significant wave height WAM-GB-2wc is reduced, especially during the Xaver peak, and is closer to the measurements.

The wind speed is validated against measured data from FINO-1 at 50 and $100 \mathrm{~m}$ height over the whole modelling period (Table 2). We find better agreement in the two-way coupled run. The bias in wind speed is negative for the one-way coupled set-up, i.e. the modelled wind speed is overestimated. The bias is significantly reduced due to the lower wind speed in the two-way coupled model. The root 
Table 3. Significant wave height $(\mathrm{m})$ bias and standard deviation of the one- and two-way coupled WAM German Bight model data against the available buoy data over the whole period (measured minus modelled). Bold means an improvement of the two-way coupled model skills; italic means that the one-way coupled model skill is better than the ones of the two-way coupled model.

\begin{tabular}{|c|c|c|c|c|c|c|c|c|}
\hline \multirow{3}{*}{$\begin{array}{l}\text { Bouy name (depth) } \\
\text { Measured } \\
\text { significant } \\
\text { wave height } \\
\text { (m) }\end{array}$} & \multicolumn{2}{|c|}{ FINO-1 (30 m) } & \multicolumn{2}{|c|}{ Elbe $(25 \mathrm{~m})$} & \multicolumn{2}{|c|}{ Helgoland (30 m) } & \multicolumn{2}{|c|}{ Sylt (13 m) } \\
\hline & \multicolumn{2}{|c|}{1.95} & \multicolumn{2}{|c|}{1.42} & \multicolumn{2}{|c|}{1.63} & \multicolumn{2}{|c|}{1.45} \\
\hline & 1-way & 2-way & 1-way & 2-way & 1-way & 2-way & 1-way & 2-way \\
\hline Bias hs (m) & -0.14 & -0.03 & -0.07 & -0.01 & -0.13 & -0.03 & -0.15 & -0.05 \\
\hline SD hs (m) & 0.45 & 0.50 & 0.49 & 0.49 & 0.54 & 0.55 & 0.59 & 0.59 \\
\hline
\end{tabular}
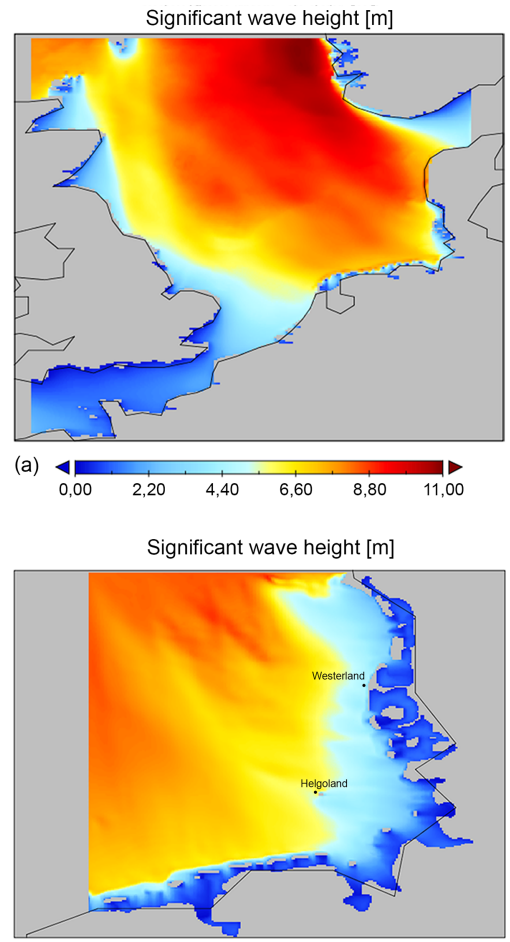

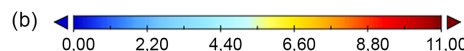

Figure 9. (a, b) Significant wave height (m) in the North Sea (a) and the German Bight (b) at the peak of storm Xaver (6 December 2013, 09:00 UTC) calculated by WAM-NS/GB-2wc.

mean square (rms) difference is $\sim 3 \mathrm{~m} \mathrm{~s}^{-1}$ in either case, but slightly reduced for the fully coupled set-up.

For a more quantitative validation of the WAM-GB$1 \mathrm{wc} / 2 \mathrm{wc}$ results, we use four buoys (see Fig. $1 \mathrm{~b}$ for their locations) at water depths of 13 to $30 \mathrm{~m}$. Table 3 gives the statistics for significant wave height over the whole period (there are $\sim 4000$ matched pairs). For the four buoys and regardless of the type of coupling, the bias is slightly negative, i.e. the modelled data overpredict the measured values. The simulated significant wave heights are lower and the bias between the measurements and model results is significantly
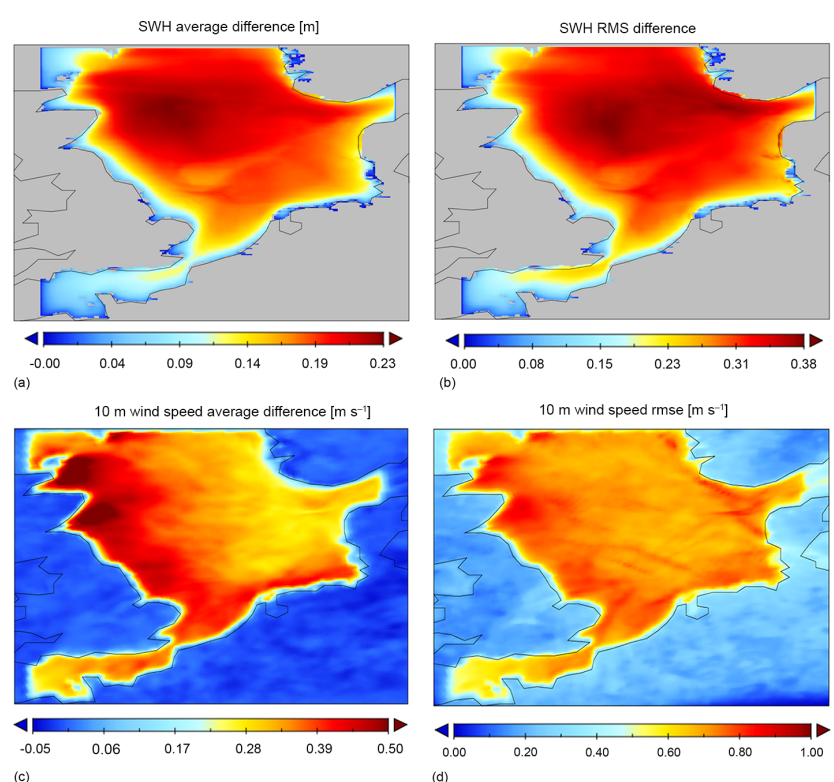

Figure 10. (a, c) Average difference and $(\mathbf{b}, \mathbf{d}) \mathrm{rms}$ difference $(\mathrm{rms}$ difference) of WAM modelled significant wave height ( $\mathrm{m}$, top panels) and COSMO modelled wind speed $\left(\mathrm{m} \mathrm{s}^{-1}\right.$, bottom panels) when comparing one-way minus two-way coupled modelling results. The differences are calculated as averages over the whole 3month period.

reduced in the WAM-GB-2wc experiment. The standard deviation of the significant wave height of the two-way coupled simulation is similar to that of the one-way coupled simulations. Only for the FINO-1 station is the standard deviation increased by $\sim 2.5 \%$ in the two-way coupled model run.

\section{Impact of the two-way coupling}

In the following discussion, the impact of coupling is analysed for the North Sea, focusing on the spatial patterns under different physical conditions. The 3-month average of the significant wave height and wind speed are reduced significantly (Fig. 10) for the two-way coupling compared to the one-way coupling. This reduction results from an extraction 


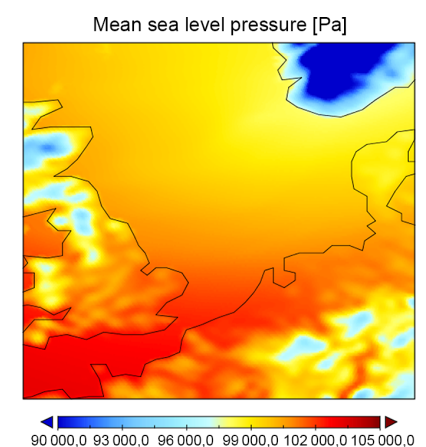

(a)

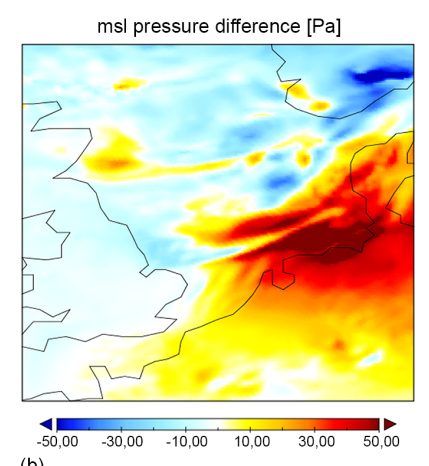

(b)
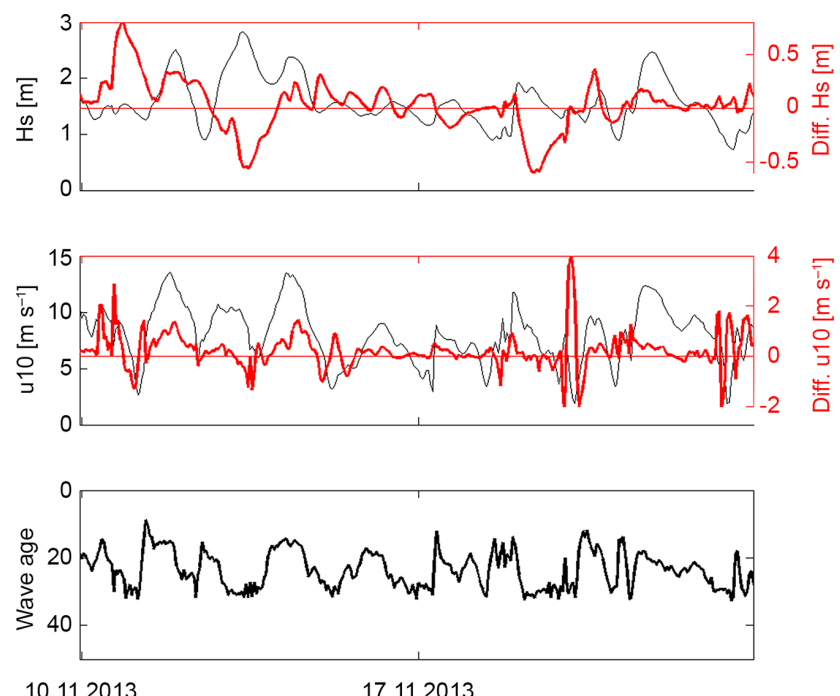

10.11 .2013

17.11 .2013

Figure 12. Time series of significant wave height (m, top panel), wind speed $\left(\mathrm{m} \mathrm{s}^{-1}\right.$, middle panel) and wave age (bottom panel) from the two-way coupled German Bight set-up at FINO-1 for (a) a rather calm period with young wind sea and (b) during storm Xaver). Red lines in the top and middle panels show the differences between the one-way and two-way coupled models.

(Fig. 10b) is $\sim 40 \mathrm{~cm}$ in the central North Sea. For the wir speeds, the averaged difference (Fig. 10c) is $\sim 30 \mathrm{~cm} \mathrm{~s}^{-1}$, corresponding to a reduction in wind speed of $\sim 3 \%$ of the 3 -month mean value $\left(\sim 10 \mathrm{~m} \mathrm{~s}^{-1}\right)$. The rms difference (Fig. 10d) between the two-way and one-way coupled simulations over the whole North Sea area is $\sim 80 \mathrm{~cm} \mathrm{~s}^{-1}$. The spatial patterns in the averaged differences in Fig. 10 can be explained by the dominant westerly winds (Fig. 2). As the wind comes from land (Great Britain) and strikes the North Sea, the differences in the wind speed between the two models are larger closer to the coast because of differences in sea surface roughness. Moving further east, the atmospheric boundary layer adapts in both cases to the winds over the sea, and there is less difference between the one- and twoway coupled models. For the wave height, the averaged differences close to the western coasts and in the English Channel are small because the fetch is too short for the waves to evolve.

The differences in the mean sea level pressure between COSMO-1wc and -2wc for the Xaver storm period are analysed in Fig. 10. At the peak of the storm (Fig. 11a) the mean sea level pressure is $\sim 900 \mathrm{hPa}$ over Norway and $\sim 1000 \mathrm{hPa}$ over the North Sea. Compared to the one-way coupled setup, the pressure increased by $\sim 50-100 \mathrm{~Pa}$ in the southeast (Fig. 11b). The slightly decreased pressure in the remaining part of the model area indicates a shift in the pressure low minimum, confirming the results of Cavaleri et al. (2012), who found similar patterns in the Mediterranean Sea under developing cyclones. As noted by Janssen and Viterbo (1996), the timescale of the wave impact on the atmospheric circulation is of the order of 5 days. However, our model area is too small to observe this impact. It is more plausible that our results are caused by wave-mean flow in-

teractions in the atmosphere. This effect of wave coupling on the atmospheric circulation will be analysed thoroughly in future experiments.

Another illustration of the influence of the coupling is given by the two time series at the FINO-1 station, each about 2 weeks long and taken under very different conditions. One period is in November, which was rather calm and contained young and developing wind seas (Fig. 12). The other period was in December, with several storms coming from the North Sea (including Xaver) with higher wave ages (Fig. 13). The differences in significant wave height and wind speed between the one- and two-way coupled models are mostly positive, i.e. both parameters are reduced in the two-way coupled model. The largest differences can be observed when the wave age (the ratio of phase velocity at the peak of the wave spectrum with friction velocity) is well below 20 and occurs before the maximum wave height has been reached (this can be well seen for Xaver, Fig. 13). Thus, the waves grow slower in the two-way coupled model. Negative differences seldom occur, only when the wave age increases rapidly (when the wind speeds approaches zero, the wave age diverges infinitely).

\section{Summary and outlook}

We developed a two-way coupled wave-atmosphere model for the North Sea including the possibility of nesting a coastal, high-resolution wave model, where the two models run simultaneously. The OASIS3-MCT coupling software 

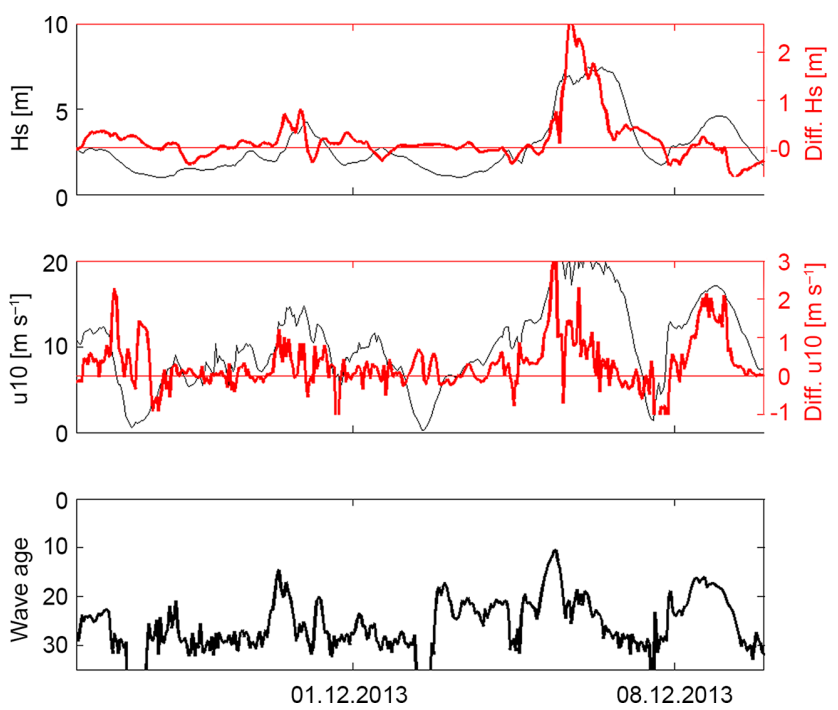

Figure 13. As Fig. 12 but during storm Xaver.

that we used allows for a parallel run of several models on different model grids. Simultaneous simulations of a regional North Sea coupled wave-atmosphere model together with a nested-grid high resolution in the German Bight wave model (one atmospheric model and two wind wave models) were performed. This enabled us to study the individual and combined effects of two-way coupling and grid resolution, especially under severe storm conditions. The sensitivity of atmospheric parameters such as wind speed and atmospheric pressure to wave-induced drag was quantified. Model intercomparisons gave encouraging results. Overall, the two-way coupled model results were in better agreement with the in situ and remotely sensed data of significant wave height and wind speed, in comparison to the one-way coupled model (COSMO drives WAM). New in this paper is the use of satellite altimetry, which provides complementary information to in situ data for the validation of models. We show that comparisons between the model results and satellite-derived parameters are satisfactory, except for a known degradation of wind speed under storm conditions, which is under investigation. The two-way coupling improved the modelled significant wave heights in the German Bight, which was demonstrated by the validation against in situ observations from four different buoys.

For storm event Xaver, the impact of the two-way coupling was of the highest significance. Wave heights decreased from $\sim 8$ to $\sim 5 \mathrm{~m}$ due to the coupling, which matched buoy measurements very well. The corresponding wind speeds were lowered from $\sim 22$ to $\sim 20 \mathrm{~m} \mathrm{~s}^{-1}$. In addition to this extreme event, such large differences between one- and two-way coupled model results were only observed for young seas (wave age well below 20). We also found a slight spatial shift in the minimum of the cyclone mean sea level pressure together with a slight increase in the pressure field from the two-way coupled model runs. These results may also have been caused by the wave-mean flow interactions in the atmosphere. This will be the subject of subsequent work, where we will study in more depth the consequences of coupling with other atmospheric parameters at sea level and the vertical structure of the planetary boundary layer.

Staneva et al. (2016) addressed the impact of coupling between wave and circulation models of the German Bight during extreme storm events. They demonstrated that the coupled model results revealed a closer match with observations than the stand-alone circulation model, especially during the Xaver extreme storm in December 2013. Staneva et al. (2016) also showed that the predicted surge of the coupled model is significantly enhanced during extreme storm events when accounting for wave-current interaction. We demonstrated that the potential uncertainties of shallow water in the wave model are due to both: inaccurate description in the bathymetry as well as the wave model source terms related to shallow water physics. Shallow water regions with the strongest wave-current interactions contribute to the coupled wave-atmosphere dynamics during extreme storm surge events. Depth and current refraction, bottom friction and wave breaking in the wave model play dominant roles in very shallow water. The model resolution is critical where the depth gradients are large. The improved model skills resulting from the new model developments justify further extension of the coupled model system by integrating atmospherewave-current interactions to further investigate the effects of coupling, especially on extreme storm events. Two-way coupling of wave and atmospheric models is an important component of a fully coupled ocean-atmosphere modelling system, as it resolves more adequately the interactions and exchanges in the atmospheric boundary layer. Accurate modelling of the boundary layer is of the utmost importance for long-range predictions.

Data availability. ARAL/AltiKa data: http://aviso.altimetry.fr, RADS data: http://rads.tudelft.nl, GPOD data: https: //gpod.eo.esa.in, WAM: http://mywave.github.io/WAM, COSMO: http://www2.cosmo-model.org/, Bathymetry: http://www.emodnet-hydrography.eu/, In-situ data used for validation: MARNET data http://www.bsh.de/de/Meeresdaten/ Beobachtungen/MARNET-Messnetz/index.jsp, BSH mooring data: http://www.bsh.de/en/Marine_data/Observations/Marine_ physical_data/moorings.jsp Model output of the pre-operational models: http://codm.hzg.de/codm/.

Competing interests. The authors declare that they have no conflict of interest.

Acknowledgements. This publication has received funding from the European Union's H2020 Programme for Research, Technological Development and Demonstration under grant agreement 
no. H2020-EO-2016-730030-CEASELESS. The authors would like to thank Arno Behrens for providing the boundary values for the wave model from his Coastal Observing System for Northern and Arctic Seas (COSYNA) results. Beate Geyer extracted boundary values from the coastDat2 database for us. Markus Schultze supported us by setting up the atmospheric model and getting it started. Ha Ho-Hagemann is supported through the REKLIM German project and the Baltic Earth Programme. Luciana Fenoglio is supported by the European Space Agency (ESA) within the Climate Change Initiative (CCI). The authors are grateful to O. Krüger for his useful comments, I. Nöhren for assistance with the graphics and the $\mathrm{BSH}$ for providing the observational data.

The article processing charges for this open-access

publication were covered by a Research

Centre of the Helmholtz Association.

Edited by: A. Sterl

Reviewed by: two anonymous referees

\section{References}

Baldauf, M., Seifert, A., Förstner, J., Majewski, D., Raschendorfer, M., and Reinhardt, T.: Operational Convective-Scale Numerical Weather Prediction with the COSMO Model: Description and Sensitivities, Mon. Weather Rev., 139, 3887-3905, 2011.

Bao, J.-W., Michelson, S. A., and Wilczak, J. M.: Sensitivity of numerical simulations to parameterizations of roughness for surface heat fluxes at high winds over the sea, Mon. Weather Rev., 130, 1926-1932, 2002.

Battjes, J. and Janssen, J.: Energy loss and set-up due to breaking of random waves, Coast. Eng. Proc., 1, 569-587, 1978.

Bidlot, J., Janssen, P., and Abdalla, S.: A revised formulation of ocean wave dissipation and its model impact, Tech. Rep. Memorandum 509, ECMWF, Reading, UK, 2007.

Breivik, Ø., Mogensen, K., Bidlot, J. R., Balmaseda, M. A., and Janssen, P. A.: Surface wave effects in the NEMO ocean model: Forced and coupled experiments, J. Geophys. Res.-Oceans, 120, 2973-2992, 2015.

Cavaleri, L., Roland, A., Dutour Sikiric, M., Bertotti, L., and Torrisi, L.: On the coupling of COSMO to WAM, in: Proceedings of the ECMWF Workshop on Ocean-Waves, 25-27 June 2012, ECMWF, Reading, 2012.

Chelton, D., Ries, J., Haines, B., Fu, L., and Callahan, P.: Satellite Altimetry in Satellite Altimetry and Earth Sciences - A Handbook of Techniques and Applications, Academic Press, San Diego, 2001.

Desjardins, S., Mailhot, J., and Lalbeharry, R.: Examination of the impact of a coupled atmospheric and ocean wave system, part I, Atmospheric aspects, J. Phys. Oceanogr., 30, 385-401, 2000.

Deutschländer, T., Friedrich, K., Haeseler, S. and Lefebvre, C.: Severe storm XAVER across northern Europe from 5 to 7 December 2013, 2013 DWD report, Deutsche Wetter Dienst, Offenbach, Germany, 2013.

Doyle, J. D.: Coupled ocean wave/atmosphere mesoscale model simulations of cyclogenesis, Tellus A, 47, 766-788, 1995.

Fenoglio-Marc, L., Dinardo, S., Scharroo, R., Roland, A., Sikiric, M. D., Lucas, B., Becker, M. Benveniste, J., and Weiss, R.: The
German Bight: A validation of CryoSat-2 altimeter data in SAR mode, Adv. Space Res., 55, 2641-2656, 2015.

Geyer, B.: High-resolution atmospheric reconstruction for Europe 1948-2012: coastDat2, Earth Syst. Sci. Data, 6, 147-164, doi:10.5194/essd-6-147-2014, 2014.

Hersbach, H. and Janssen, P. A. E. M.: Improvements of the short fetch behaviour in the WAM model, J. Atmos. Ocean. Tech., 16, 884-892, 1999.

Ho-Hagemann, H. T. M., Rockel, B., Kapitza, H., Geyer, B., and Meyer, E.: COSTRICE - an atmosphere-ocean-sea ice model coupled system using OASIS3, HZG Report 2013-5, HelmholtzZentrum Geesthacht, Geesthacht, 26 pp., 2013.

Janssen, P. A. E. M.: Quasi-linear theory of wind-wave generation applied to wave forecasting, J. Phys. Oceanogr., 21, 1631-1642, 1991.

Janssen, P. A. E. M.: Progress in ocean wave forecasting, J. Comput. Phys., 227, 3572-3594, 2008.

Janssen, P. A. E. M. and Viterbo, P.: Ocean waves and the atmospheric climate, J. Climate, 9, 1269-1287, 1996.

Janssen, P. A. E. M., Saetra, O., Wettre, C., Hersbach, H., and Bidlot, J.: Impact of the sea state on the atmosphere and ocean, Ann. Hydrogr., 772, 143-157, 2004.

Järvenoja, T. and Tuomi, L.: Coupled atmosphere-wave model for FMI and FIMR, Hirlam Newsletter, 40, 9-22, 2002.

Jenkins, A., Bakhoday Paskyabi, M., Fer, I., Gupta, A., and Adakudlu, M.: Modelling the effect of ocean waves on the atmospheric and ocean boundary layers, Energy Procedia, 24, 166175, 2012.

Katsafados, P., Papadopoulos, A., Korres, G., and Varlas, G.: A fully coupled atmosphere-ocean wave modeling system for the Mediterranean Sea: interactions and sensitivity to the resolved scales and mechanisms, Geosci. Model Dev., 9, 161-173, doi:10.5194/gmd-9-161-2016, 2016.

Komen, G. J., Cavaleri, L., Donelan, M., Hasselmann, K., Hasselmann, S., and Janssen, P. A. E. M.: Dynamics and modelling of ocean waves, Cambridge University Press, Cambridge, UK, 560 pp., 1994.

Kumar, N., Voulgaris, G., Warner, J. C., and Olabarrieta, M.: Implementation of the vortex force formalism in the coupled oceanatmosphere-wave-sediment transport (COAWST) modeling system for inner shelf and surf zone applications, Ocean Model., 47, 65-95, 2012.

Lillibridge, J. L., Scharroo, R., Abdalla, S., and Vandemark, D. C.: One- and two-dimensional wind speed models for Ka-band altimetry, J. Atmos. Ocean. Tech., 31, 630-638, doi:10.1175/JTECH-D-13-00167.1, 2014.

Lionello, P., Malguzzi, P., and Buzzi, A.: Coupling between the atmospheric circulation and the ocean wave field: An idealized case, J. Phys. Oceanogr., 28, 161-177, 1998.

Lionello, P., Elvini, E., and Nizzero, A.: Ocean waves and storm surges in the Adriatic Sea: intercomparison between the present and doubled $\mathrm{CO}_{2}$ climate scenarios, Clim. Res., 23, 217-231, 2003.

Passaro, M., Fenoglio-Marc, L., and Cipollini, P.: Validation of Significant Wave Height From Improved Satellite Altimetry in the German Bight, IEEE T. Geosci. Remote, 53, 2146-2156, 2015.

Renault, L., Chiggiato, J., Warner, J. C., Gomez, M., Vizoso, G., and Tintoré, J.: Coupled atmosphere-ocean-wave simulations of 
a storm event over the Gulf of Lion and Balearic Sea, J. Geophys. Res., 117, C09019, doi:10.1029/2012JC007924, 2012.

Rockel, B., Will, A., and Hense, A.: The Regional Climate Model COSMO-CLM (CCLM), Meteorol. Z., 17, 347-348, 2008.

Rutgersson, A., Sætra, Ø., Semedo, A., Carlsson, B., and Kumar, R.: Impact of surface waves in a regional climate model, Meteorol. Z., 19, 247-257, 2010.

Rutgersson, A., Nilsson, E. O., and Kumar, R.: Introducing surface waves in a coupled wave-atmosphere regional climate model: Impact on atmospheric mixing length, J. Geophys. Res.-Oceans, 117, C00J15, doi:10.1029/2012JC007940, 2012.

Scharroo, R., Leuliette, E. W., Lillibridge, J. L., Byrne, D., Naeije, M. C., and Mitchum, G. T.: RADS: consistent multi-mission products, in: Proc. of the Symposium on 20 Years of Progress in Radar Altimetry, 24-29 September 2012, Venice-Lido, Italy, 2013.

Smith, W. H. F. and Scharroo, R.: Waveform aliasing in satellite radar altimetry, IEEE T. Geosci. Remote., 53, 1671-1681, doi:10.1109/TGRS.2014.2331193, 2015.

Staneva, J., Behrens, A., and Wahle, K.: Wave modelling for the German Bight coastal-ocean predicting system, J. Phys., 633, 233-254, doi:10.1088/1742-6596/633/1/012117, 2015.
Staneva, J., Wahle, K., Günther, H., and Stanev, E.: Coupling of wave and circulation models in coastal-ocean predicting systems: a case study for the German Bight, Ocean Sci., 12, 797806, doi:10.5194/os-12-797-2016, 2016.

Valcke, S.: The OASIS3 coupler: a European climate modelling community software, Geosci. Model Dev., 6, 373-388, doi:10.5194/gmd-6-373-2013, 2013.

Valcke, S., Craig, T., and Coquart, L.: OASIS3-MCT User Guide, OASIS3-MCT 2.0, Technical Report, TR/CMGC/15/38, No. 1875, CERFACS/CNRS SUC URA, Toulouse, France, 2013.

Voldoire, A., Sanchez-Gomez, E., Mélia, D. S., Decharme, B., Cassou, C., Sénési, S., and Déqué, M.: The CNRM-CM5.1 global climate model: description and basic evaluation, Clim. Dynam., 40, 2091-2121, 2013.

Warner, J. C., Armstrong, B., He, R., and Zambon, J. B.: Development of a coupled ocean-atmosphere-wave-sediment transport (COAWST) modeling system, Ocean Model., 35, 230-244, 2010.

Zweers, N. C., Makin, V. K., de Vries, J. W., and Burgers, G.: A sea drag relation for hurricane wind speeds, Geophys. Res. Lett., 37, L21811, doi:10.1029/2010GL045002, 2010. 